\title{
The characteristics of sexual behaviour and extent of condom usage among sexually active Croatians from Eastern Croatia, letter to the editor
}

\author{
Doğu Hırvatistandaki cinsel aktif kadınlann kondom kullanımı hakkındaki görüşleri ve \\ cinsel dauranış biçimleri, editöre mektup
}

\author{
Emre Karaşahin, Cihangir Mutlu Ercan, İbrahim Alanbay, İskender Başer \\ Gulhane Military Medical Academy Department of Obstetrics and Gynecology, Ankara, Turkey
}

Dear Sir,

We have read "The characteristics of sexual behaviour and extent of condom usage among sexually active Croatians from Eastern Croatia" by Miskulin et al (1), in the J TurkishGerman Gynecol. Assoc. 2009, 10; 142-7 with interest.

The authors have put considerable efforts into their study and they draw attention to the risky sexual behaviour of a certain Croatian population and stated their study was the first attempt in this aspect.

They have used a 20 question questionnaire to collect data for their study. While this questionnaire provided valuable data, the question number 12, "I have NEVER in my lifetime involved myself in sexual activities combined with drug or alcohol abuse without condom: a) yes b) no" is a CRITICAL question in this questionnaire.

As far as we are concerned, the answers of the subjects to this question have not been mentioned in the text of the article. Gender differences notwithstanding, the qualitative data generally suggest that alcohol use before sex leads to uninhibited sexual behavior, including increased sexual arousal, increased likelihood for participating in casual sex, and increased confidence and flirtation with the opposite sex in both men and women. Furthermore, the situational use of alcohol was found to be related to inconsistent or non-use of condoms and increased difficulty to implement condom use (2).

We believe authors should have presented their data about risky sexual behaviour associated with alcohol and/or drug use in their manuscript. However, this could also, be another topic to be discussed separately.

Another interesting data would have been the association of risky sexual behaviour with Hepatitis $\mathrm{B}$, which is also found in the questionnaire, but has not been mentioned in the text. Hepatitis B is classified as a sexually transmitted infection (3). It would be interesting to learn about the Hepatitis B immune or non immune people's sexual behaviour and preferences, since Hepatitis B is a major health concern in some parts of the world. The authors mentioned risky sexual behaviour but have not defined what should be considered as risky sexual behaviour. For convenience, a definition would be: Unprotected intercourse without male or female condom use, except in a longterm, monogamous relationship, unprotected mouth-to-genital contact, except in a long-term monogamous relationship, early sexual activity, especially before age 18, having multiple sex partners, having a high-risk partner (one who has multiple sex partners or other risk factors), having anal sex or a partner who does, except in a long-term, monogamous relationship, having sex with a partner who injects or has ever injected drugs, exchange of sex (sex work) for drugs or money (4).

We would like to thank the authors for sharing their valuable data with us.

Sincerely

Conflict of interest

None declared

\section{References}

1. The characteristics of sexual behavior and extent of condom usage among sexually active Croatians from Eastern Croatia Miskulin M, Miskulin I, Puntaric D, Mujkic A, Milas J, Bosnjak N. J. Turkish - German Gyencol. Assoc 2009, 10; 142-7.

2. Woolf-King SE, Maisto SA Alcohol Use and High-Risk Sexual Behavior in Sub-Saharan Africa: A Narrative Review Arch Sex Behav DOI 10.1007/s10508-009-9516-4. Published online in 25 August 2009.

3. Phillip Hay P, Ugwumadu A. Detecting and treating common sexually transmitted diseases Best Practice \& Research Clinical Obstetrics and Gynaecology . 2009; 23: 647-60.

4. http://www.revolutionhealth.com/articles/high-risk-sexual-behavior/tw9064. Certified by Health on the Net association (HONConduct274933). 